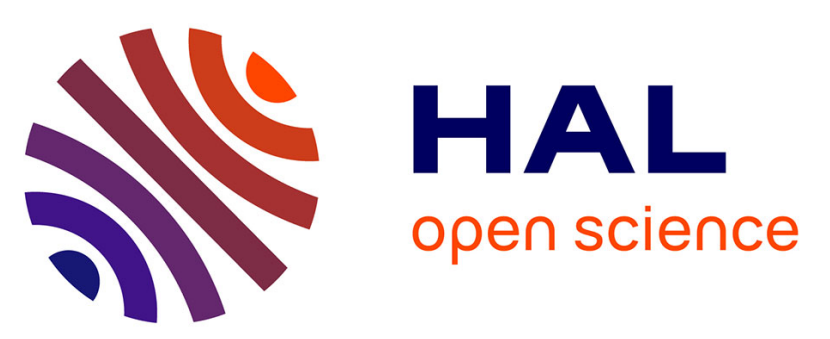

\title{
Mechanisms of deformation in gum metal TNTZ-O and TNTZ titanium alloys: A comparative study on the oxygen influence \\ Magali Besse, Philippe Castany, Thierry Gloriant
}

\section{- To cite this version:}

Magali Besse, Philippe Castany, Thierry Gloriant. Mechanisms of deformation in gum metal TNTZ-O and TNTZ titanium alloys: A comparative study on the oxygen influence. Acta Materialia, 2011, 59 (15), pp.5982-5988. 10.1016/j.actamat.2011.06.006 . hal-00926966

\section{HAL Id: hal-00926966 https://hal.science/hal-00926966}

Submitted on 13 Jan 2014

HAL is a multi-disciplinary open access archive for the deposit and dissemination of scientific research documents, whether they are published or not. The documents may come from teaching and research institutions in France or abroad, or from public or private research centers.
L'archive ouverte pluridisciplinaire HAL, est destinée au dépôt et à la diffusion de documents scientifiques de niveau recherche, publiés ou non, émanant des établissements d'enseignement et de recherche français ou étrangers, des laboratoires publics ou privés. 


\title{
Mechanisms of deformation in gum metal TNTZ-O and TNTZ titanium alloys: A comparative study on the oxygen influence
}

\author{
M. Besse, P. Castany, T. Gloriant \\ INSA Rennes, UMR CNRS 6226 SCR/Chimie-Métallurgie, 20 avenue des Buttes de \\ Coësmes, 35708 Rennes Cedex 7, France
}

\begin{abstract}
In this work, Ti-23Nb-0.7Ta-2Zr (TNTZ) and gum metal Ti-23Nb-0.7Ta-2Zr-1.2O (TNTZ-O) alloys were synthesized by cold crucible levitation melting with the objective of investigating the influence of oxygen on the deformation mechanisms. By tensile tests, electron backscatter diffraction, atomic force microscopy and transmission electron microscopy analyses, we showed that the deformation in the TNTZ-O alloy is only accommodated by dislocation slip. Thus, the addition of oxygen suppresses the formation of $\alpha^{\prime \prime}$ martensite and prevents the twinning deformation mechanism, which were both observed in the TNTZ alloy. In addition, in situ tensile tests in a transmission electron microscope showed that conventional $a / 2\left\langle\begin{array}{llll}1 & 1 & 1\end{array}\right\rangle$ dislocation slip occurs widely in the TNTZ-O alloy. Screw dislocations have a lower mobility than non-screw dislocations. Cross-slip is shown to be easy and multiplication of dislocations by a double cross-slip mechanism occurs extensively, leading to the formation of large slip bands.
\end{abstract}

Keywords: Titanium alloys; Microstructure; Tensile tests; Electron backscatter diffraction (EBSD); Transmission electron microscopy (TEM) 


\section{Introduction}

Among the beta-type Ti-based alloys, the multifunctional $\mathrm{Ti}-23 \mathrm{Nb}-0.7 \mathrm{Ta}-2 \mathrm{Zr}-1.2 \mathrm{O}$ alloy composition (mol.\%), called "gum metal" and first elaborated by Saito et al. in 2003 [1], was shown to possess "super" properties, such as very high strength, low Young's modulus, superelasticity and superplasticity at room temperature. Some of these properties are obtained after cold working. These properties make this alloy an excellent candidate for various applications, such as in the automotive, aeronautic and biomedical sectors.

It is claimed that this alloy deforms through unconventional dislocation-free mechanisms: "nanodisturbances" and "giant faults" [1]. These mechanisms are responsible for the alloy's exceptional properties, and no dislocation slip-, twinning- or stress-induced martensite is thought to carry the deformation [2], [3], [4] and [5]. The plastic deformation is accommodated only by the growth of nanodisturbances and the formation of giant faults (pure shear bands) without any dislocation slip. The activation of such unconventional mechanisms is possible because this alloy exhibits an ideal shear strength lower than the critical shear stress of conventional dislocation slip. This is due to the combination of a very low ideal shear strength, caused by the instability of the $\beta$ phase vs. the $\alpha-\beta$ transformation, and a high critical shear stress of conventional dislocations, caused by the presence of a large density of nanometric pinning defects. These obstacles inhibit the motion of dislocations and are supposed to be clusters of $\mathrm{ZrO}$ [1] or nanometric $\omega$ phase [6] and [7].

However, the mechanism of deformation of such an alloy is a subject of discussion in the recent literature. Indeed, further studies have shown that dislocations are present in this alloy [8], [9], [10] and [11], but no clear evidence of their role in the plastic deformation has been highlighted. In addition, some $\left\{\begin{array}{lll}1 & 1 & 2\end{array}\right\}\left\langle\begin{array}{lll}1 & 1 & 1\end{array}\right\rangle$ or $\left\{\begin{array}{lllll}3 & 3 & 2\end{array}\right\}\left\langle\begin{array}{llll}1 & 1 & 3\end{array}\right\rangle$ twins have been also observed [11], [12] and [13], as well as some stress-induced $\omega$ plates [11], [12] and [14]. A reversible stress-induced martensitic transformation (SIM) from $\beta$ to $\alpha$ " has also been shown by in situ X-ray diffraction tensile tests [13] and [14]. This transformation is responsible of the superelasticity of gum metals. Another mechanism of superelasticity would be the reversible nucleation of nanometric dislocation loops, which are equivalent to nanodisturbances [15]. Nowadays, studies on the origin of the properties of gum metals and the different mechanisms of deformation even contradict themselves.

In this study, we have synthesized this alloy composition by a melting process, contrary to the original alloy, which was produced by sintering. Two objectives of this study were to show if the "super" mechanical properties of this alloy composition could still be obtained by this 
alternative way of processing and to investigate its mechanisms of deformation. For this, uniaxial tensile tests and cyclic tests were performed on normalized specimens. Then, electron backscatter diffraction (EBSD), atomic force microscopy (AFM) observations and X-ray diffraction (XRD) were performed after deformation to determine precisely the mechanisms of deformation. In situ tensile experiments in transmission electronic microscopy (TEM) were also carried out on the gum metal $\mathrm{Ti}-23 \mathrm{Nb}-0.7 \mathrm{Ta}-2 \mathrm{Zr}-1.2 \mathrm{O}$ alloy. In addition, the deformation mechanism of the gum metal alloy was investigated and compared with the Ti$23 \mathrm{Nb}-0.7 \mathrm{Ta}-2 \mathrm{Zr}$ alloy composition without oxygen. Understanding the influence of the oxygen element on the mechanisms of deformation was the main objective of this work.

\section{Materials and methods}

As titanium, zirconium, tantalum and niobium have very different melting points and densities, the synthesis of both alloy compositions (mol.\%), i.e. the gum metal $\mathrm{Ti}-23 \mathrm{Nb}-$ $0.7 \mathrm{Ta}-2 \mathrm{Zr}-1.2 \mathrm{O}$ (TNTZ-O) and $\mathrm{Ti}-23 \mathrm{Nb}-0.7 \mathrm{Ta}-2 \mathrm{Zr}$ (TNTZ), was realized by the cold crucible semi-levitation melting (CCLM) technique under high vacuum, using a highfrequency magnetic induction generator heating system (CELES). With this method, the highfrequency magnetic field is used to stir the liquid, which is useful in that it ensures that the alloying elements are fully mixed into the melt without contamination by restricting the contact points between the melt and the cold crucible [16]. The added elements are pure solid metals, except oxygen, which was introduced through titanium oxide $\left(\mathrm{TiO}_{2}\right)$ powder. After a homogenization treatment at $950^{\circ} \mathrm{C}$ for $16 \mathrm{~h}$, samples were cold rolled to $90 \%$ in thickness. Then all the samples were solution treated at $850{ }^{\circ} \mathrm{C}$ for $0.5 \mathrm{~h}$ in the beta-phase field and quenched in water. The aim of this treatment was to restore a fully recrystallized microstructure from the cold-rolled state.

Phase analyses of both alloys were carried out by XRD with a Philips PW3710 diffractometer using $\mathrm{Cu} \mathrm{K \alpha} \alpha_{1}$ radiation $(\lambda=0.154060 \mathrm{~nm})$. An optical microscope (Leica) was used to observe the recrystallized microstructures. For this, samples were successively mechanically polished with different $\mathrm{SiC}$ abrasive papers until grade 4000. The "mirror-polished" state was obtained using a colloidal silica suspension (particles size: $50 \mathrm{~nm}$ ). Each microstructure was revealed by chemical etching with a solution composed of $5 \% \mathrm{HF}, 5 \% \mathrm{HNO}_{3}$ and $90 \% \mathrm{H}_{2} \mathrm{O}$. EBSD investigations were carried out by scanning electron microscopy (SEM) using a Jeol JSM 6400 scanning electron microscope equipped with a TSL camera. 
Conventional and cyclic tensile tests were carried out at room temperature on both alloys using an INSTRON 3369 tensile machine (strain rate: $10^{-4} \mathrm{~s}^{-1}$ ). An extensometer was used to record precisely the deformation. For cyclic tests, loads were incremented by $0.5 \%$ between $0 \%$ and $3 \%$ of deformation, and then by $1 \%$ up to $5 \%$ of deformation. The tensile test specimens possess a normalized rectangular shape: $3 \mathrm{~mm}$ width, $0.5 \mathrm{~mm}$ thickness and $15 \mathrm{~mm}$ gage length.

AFM (CSM instrument) observations were done on previously polished specimens before tensile tests in order to show the "real" surface state after deformation. TEM observations were performed on a JEOL 2010 working with an accelerating voltage of $200 \mathrm{kV}$. A videorate SIS CCD camera and a Gatan straining holder were used for in situ straining experiments. Samples were thinned with a Struers twin jet electropolishing system in a solution of $6 \%$ perchloric acid, 59\% methanol and 35\% 2-butoxyethanol (vol.\%).

\section{Results and discussion}

\subsection{As-quenched recrystallized microstructures}

Typical microstructures of TNTZ and TNTZ-O alloys observed by optical microscopy are shown in Fig. 1. Both alloys present an equiaxed microstructure consisting of $\beta$ grains a few tens of micrometers in size. In TNTZ alloy, additional fine needle-like precipitates are observable in the $\beta$ grains (Fig. 1a). In contrast, the gum metal TNTZ-O seems to show a pure equiaxed $\beta$ grain microstructure (Fig. 1b). The alloys were characterized by XRD and the related diffraction patterns are presented in Fig. 2. It is confirmed that the TNTZ-O alloy processes a single-phase $\beta$ microstructure since only the peaks related to the body-centered cubic (bcc) $\beta$ phase are present. Needle-like precipitates observed in the TNTZ alloy were found to be related to the C-centered orthorhombic $\alpha$ " martensitic phase. It is not surprising that this phase, which was formed during the water quenching, was obtained, as quenched $\alpha^{\prime \prime}$ martensite formation has been observed previously in numerous $\beta$ titanium alloys of similar composition [17], [18] and [19]. Thus, by comparing the two studied alloys, we have shown that the formation of quenched martensite $\alpha$ " phases is suppressed by the addition of oxygen. 


\subsection{Tensile tests}

The mechanical properties of both alloys were evaluated by tensile tests, and typical stressstrain curves are shown in Fig. 3. Fig. 3a presents the conventional tensile curves, while the cyclic tensile curves are shown in the Fig. 3b. A drastic difference in behavior between the alloys is highlighted from these curves.

The tensile curve related to the TNTZ alloy presents the typical double yielding behavior seen in pseudo-elastic $\beta$-type Ti-alloys [17]. With these kinds of alloy, superelastic and shape memory behaviors can be obtained due to the presence of the $\alpha^{\prime \prime}$ martensite phase. In the present case, the plateau is characteristic of the reorientation of $\alpha^{\prime \prime}$ martensite variants initially present in the recrystallized and quenched state since a relatively low elastic recovery estimated at $0.25 \%$ is obtained. The TNTZ alloy then presents the characteristic of a shapememory alloy. This kind of alloy is usually very ductile - as it is in the present case, since an elongation at rupture above $30 \%$ was measured. With the addition of oxygen in the TNTZ-O alloy, such a plateau in the stress-strain tensile curve is not observed. This is due to the fact that the $\alpha^{\prime \prime}$ phase is no longer present in the gum metal TNTZ-O alloy in its quenched state. However, the alloy possesses a non-linear elastic deformation. This distinctive peculiarity is in good agreement with the results published previously for this alloy [1] and [4]. For the TNTZ-O alloy, a high strengthening effect is observed by comparison with the TNTZ alloy. Thus, a yield strength evaluated at $830 \mathrm{MPa}$ is observed and a reversible elastic deformation as high as $1.7 \%$ is obtained, confirming the claimed "superelastic" property of this alloy. The second peculiarity in the TNTZ-O alloy behavior affects the flat part of the plastic deformation. Indeed, contrary to the TNTZ alloy, where stress continues to increase during deformation, it appears that there is a lack of consolidation in the plastic deformation in TNTZ-O. This could be explained by the heterogeneity of the deformation, as will be confirmed further by AFM and in situ TEM observations.

The mechanical properties measured from these tensile curves are grouped in Table 1 and compared to the values of the originally sintered TNTZ-O alloy elaborated by Saito et al. [1]. It is worth noting that the mechanical properties of the gum metal TNTZ-O alloy are very similar to those obtained by Saito et al., despite the different processing route used: CCLM instead of elemental powder sintering. 


\subsection{Mechanisms of deformation}

Generally, the mechanisms of deformation of $\beta$ titanium alloys vary depending on the stability of the alloys [20]. The main mechanisms of deformation of this phase are dislocation slip, twinning and SIM. In this work, microstructures of the gum metal TNTZ-O and TNTZ were observed on tensile specimens deformed at rupture by SEM and EBSD. Then AFM observations and in situ TEM tensile tests were performed on the TNTZ-O alloy, in order to determine the different mechanisms of deformation.

The SEM image presented in Fig. 4 shows the microstructure of the TNTZ alloy after its rupture at $33 \%$ of elongation. The surface of this deformed alloy exhibits large bands of deformation. Finer, though similar, lines are also visible, and are related to dislocation slip.

Characterization by EBSD was performed to investigate the nature of these large bands of deformation (Fig. 5). An example of a typical EBSD inverse pole figure (IPF) map is presented in Fig. 5a. The analysis of the large bands showed that the boundaries between $\beta$ grain and these bands were $\Sigma 3$ coincidence site lattice boundaries. Profile misorientation carried out along the line $\mathrm{AB}$ (Fig. 5b) shows disorientation of around $60^{\circ}$. It is known that such characteristics in the $\beta$-type Ti alloys (body-centered cubic crystal structure) correspond to the twinning system $\left\{\begin{array}{lll}1 & 1 & 2\end{array}\right\}\left\langle\begin{array}{lll}1 & 1 & 1\end{array}\right\rangle$. This twinning system has been confirmed by the analysis of common poles of the two crystals on pole figures 112 and 111. Consequently, three mechanisms of deformation occur in the TNTZ alloy: a reorientation of the quenched $\alpha^{\prime \prime}$ martensitic phase occurs at the first stage of deformation, and is followed after the second yielding by conventional dislocation glide and $\left\{\begin{array}{lll}1 & 1 & 2\end{array}\right\}\left\langle\begin{array}{lll}1 & 1 & 1\end{array}\right\rangle$ twinning. The present results confirmed previous studies on similar alloys [19] and [21].

EBSD investigations were also conducted in the TNTZ-O alloy after deformation and typical EBSD maps are presented in Fig. 6. The large bands observed in the TNTZ alloy are no longer visible in the deformed TNTZ-O alloy composition after its rupture at $14 \%$ of elongation. As an example, the EBSB IPF map presented in Fig. 6a shows only the $\beta$-grain microstructure without any presence of twinning. Only very fine straight lines crossing all the grains are observed in the deformed alloy, as shown on the EBSD image quality (IQ) map in Fig. 6b. The nature of theses lines could be attributed to the $\alpha^{\prime \prime}$ phase as SIM is sometimes reported in TNTZ-O [13]. However, XRD analysis did not indicate the presence of such a phase. Consequently, these lines can be definitely attributed to dislocation slip bands in the present alloy. 
These lines of deformation were also observed by AFM (Fig. 7). The observations were made on specimens previously mirror polished without chemical etching and then deformed in tension up to $14 \%$ (at rupture). Both strong distortion of the grains and deformation lines are observed with a significant relief (Fig. 7a). Thus, it is possible to estimate the actual height of the steps created at the surface. An example of a profile along the line $\mathrm{AB}$ and crossing through the traces of deformation is shown in Fig. 7b. The profile indicates a heterogeneous displacement across the steps characteristic of slip bands, whereas plates of martensitic phase or twinning would be characterized by a uniform displacement across the steps [22] and [23]. So, such a profile looks like slip lines grouped to form slip bands. Similar lines have already been observed by optical microscopy on the surface of $\mathrm{Ti}-35 \mathrm{Nb}-10 \mathrm{Ta}-5 \mathrm{Zr}$ (wt.\%) and were also attributed to traces of slip by Niinomi et al. [24].

To confirm that these lines are slip traces, their crystallographic orientations were determined by combining AFM observations and EBSD analyses to determine grain orientations. The stereographic projection corresponding to each grain was established from the EBSD data. The directions of the slip traces of all the possible slip systems were next determined and compared to the directions observed by AFM. In most of the grains, the deformation lines correspond clearly to $\left\{\begin{array}{lllll}1 & 1 & 0\end{array}\right\}$ or $\left\{\begin{array}{llll}1 & 1 & 2\end{array}\right\}$ planes. As the $\left\{\begin{array}{llll}1 & 1 & 0\end{array}\right\}$ traces correspond unambiguously to slip traces and as the $\left\{\begin{array}{lll}1 & 1 & 2\end{array}\right\}$ traces have the same morphology, all the deformation lines observed can be definitively attributed to slip traces. It is also worth noting that slip traces in some grains correspond to $\left\{\begin{array}{lll}3 & 2 & 1\end{array}\right\}$ slip planes.

In order to observe the dislocation scale, in situ TEM tensile experiments were also carried out in the gum metal TNTZ-O alloy. Before deformation, a fully recrystallized $\beta$ microstructure is observed by TEM without any presence of quenched $\alpha^{\prime \prime}$ martensite, confirming our previous observations. During the in situ deformation stage, dislocation glide appears without observing SIM or twinning. Fig. 8 shows a typical TEM micrograph taken from a video-recording during an in situ experiment. It can be seen that most of the dislocations glide in slip bands (SB), though some single dislocations also glide in the grain. The Burgers vector of all mobile dislocations determined by regular indexation method using the $\mathrm{g} . \mathrm{b}=0$ criterion is found to be $a / 2\left\langle\begin{array}{lll}1 & 1 & 1\end{array}\right\rangle$. Slip planes were determined from slip traces left by dislocations at the surfaces of the specimen (Fig. 8). Slip planes of $a / 2\left\langle\begin{array}{lll}1 & 1 & 1\end{array}\right\rangle$ dislocations are thus characterized to be $\left\{\begin{array}{lll}1 & 1 & 0\end{array}\right\}$ or $\left\{\begin{array}{lll}1 & 1 & 2\end{array}\right\}$ planes. It was often observed that several different slip systems operated in the same grain. Some slip traces are wavy, which is 
due to multiple cross-slips, as evidenced by the trace of the single dislocations in the middle of Fig. 8, whereas other traces are very straight.

It is also observed that the velocity of non-screw segments is much higher than that of the screw segment, which leads quickly to a large density of straight screw dislocations. The typical motion of screw segments is illustrated by the in situ TEM sequence presented in Fig. 9. It is shown that some parts of the screw segments jump quickly from a previous position (marked with dashed lines) to a new position. Between successive jumps, the dislocation remains perfectly immobile (video available online as Supplementary material). This motion is characteristic of a mobility lowered by a three-dimensional core structure of screw dislocations that locks the dislocation before the fast motion to another position. This mechanism has been observed in pure bcc iron at low temperature [25] or in the hexagonal close-packed $\alpha$ phase in titanium alloys at room temperature [26], [27] and [28]. In addition, this figure shows a multiplication of screw dislocations: the dislocation is first pinned (white arrow in Fig. 9a) and leaves a loop behind after slipping away (white arrow in Fig. 9d). This loop then expands further under the applied stress (Fig. 9e). This mechanism of multiplication is due to multiple cross-slips [27] and [29] and confirms the facility for dislocations to crossslip, as pointed out by analysis of the slip traces. Extensive occurrence of this multiplication mechanism leads quickly to the formation of large slip bands (marked SB in Fig. 8) separated by areas where no or little plastic activity takes place. These are the slip bands that we had previously observed by SEM/EBSD and AFM. These heterogeneous bands of deformation are also in agreement with the curves of tensile tests having a very flat shape in the plastic deformation.

With these in situ TEM observations, dislocation slip has been unambiguously shown to take place in the plastic deformation of the gum metal TNTZ-O alloy. On the other hand, no other deformation mechanisms, such as SIM or twinning, have been observed. It is thus clear that the role of oxygen is predominant in the deformation mechanisms of this alloy. The fact that the $\alpha^{\prime \prime}$ martensite formation does not occur in the present TNTZ-O alloy is not surprising as oxygen is known to have a strong influence on the $\alpha$ " martensitic transformation in $\beta$-type Ti alloys [30] and [31]. Thus, the martensitic transformation temperature was shown to decrease by $160 \mathrm{~K}$ per $1 \mathrm{~mol} . \%$ increase in oxygen content in Ti-22Nb alloy [30]. With the present TNTZ-O alloy composition, both the quantity of the $\beta$-stabilizing element and the oxygen content seem to be high enough to avoid the $\alpha^{\prime \prime}$ martensitic transformation. 
As twinning is activated in the TNTZ alloy and not in the TNTZ-O alloy, it can be concluded that the addition of oxygen inhibits mechanical twinning during deformation. The effect of oxygen addition on $\left\{\begin{array}{lll}1 & 1 & 2\end{array}\right\}\left\langle\begin{array}{llll}1 & 1 & 1\end{array}\right\rangle$ twinning has not been reported in $\beta$ titanium alloys, but it is known that the addition of interstitial elements in bcc metals removes twinning as a deformation mechanism [32]. Indeed, the formation of twins in bcc metals with interstitials requires the additional shuffling of interstitial atoms, which is energetically prohibitive, leading to the suppression of deformation twinning. In TNTZ alloy, the same effect is thus observed and the addition of oxygen in the TNTZ-O alloy increases the critical shear stress of twinning, which is suppressed as a deformation mechanism.

The reason for the TNTZ-O alloy showing non-linear elastic deformation in the present case remains unclear. Indeed, according to the literature [13], [14] and [33], the non-linear elastic deformation is supposed to be due to the $\alpha$ " SIM, but this transformation was not observed here. On the other hand, non-linear elastic deformation has also been reported in the $\mathrm{Ti}-$ $24 \mathrm{Nb}-4 \mathrm{Zr}-8 \mathrm{Sn}$ alloy (in mass \%), and was shown to be related to easy crystal distortion due to the greatly weakened chemical bonding of atoms in the bcc crystal [34] and [35]. Thus, the mechanism of elastic deformation in such alloys remains ambiguous and further investigations are needed to understand this non-linear behavior.

\section{Conclusions}

$\mathrm{Ti}-23 \mathrm{Nb}-0.7 \mathrm{Ta}-2 \mathrm{Zr}$ (TNTZ) and gum metal Ti-23Nb-0.7Ta-2Zr-1.2O (TNTZ-O) alloys were synthesized by CCLM in this work. The first alloy contains a two-phase $\beta+\alpha^{\prime \prime}$ microstructure, and the second is purely $\beta$ in the recrystallized/quenched state. The addition of oxygen suppresses the $\alpha^{\prime \prime}$ martensitic phase, which leads to very different behavior during tensile tests.

The tensile curve of the TNTZ alloy shows the presence of a plateau due to the reorientation of the $\alpha^{\prime \prime}$ martensite variants in the initial state. After the second yielding, it was shown that the deformation is accommodated by conventional dislocation glide and $\left\{\begin{array}{lllll}1 & 1 & 2\end{array}\right\}\left\langle\begin{array}{llll}1 & 1 & 1\end{array}\right\rangle$ twinning.

The gum metal TNTZ-O alloy presents a very high yield strength at $830 \mathrm{MPa}$, with a corresponding recoverable "superelastic" deformation of $1.7 \%$. The tensile properties of the TNTZ-O alloy produced in this work by CCLM are similar to those initially produced by elemental powder sintering. On the other hand, we showed that the deformation in the TNTZ- 
$\mathrm{O}$ alloy is not accommodated by twinning. Thus, it can be concluded that the addition of oxygen to TNTZ-O suppresses the formation of $\alpha^{\prime \prime}$ martensite and deformation twinning. In situ TEM tensile experiments clearly show that unconventional dislocation-free mechanisms do not occur during the plastic deformation of this gum metal TNTZ-O alloy. Deformation is shown to be caused only by conventional dislocation slip. The deformation rate is then controlled by the low mobility of screw $a / 2\left\langle\begin{array}{llll}1 & 1 & 1\end{array}\right\rangle$ dislocations, as commonly observed in bcc metals. This low mobility is attributed to their three-dimensional core structure.

\section{Acknowledgements}

The authors acknowledge financial support from the French CNRS and CEA METSA network for in situ TEM experiments.

\section{References}

[1] Saito T, Furuta T, Hwang J-H, Kuramoto S, Nishino K, Suzuki N, Chen R, Yamada A, Ito

K, Seno Y, Nonaka T, Ikehata H, Nagasako N, Iwamoto C, Ikuhara Y, Sakuma T. Science 2003;300:464.

[2] Gutkin MY, Ishizaki T, Kuramoto S, Ovid'ko IA. Acta Mater 2006;54:2489.

[3] Kuramoto S, Furuta T, Hwang J, Nishino K, Saito T. Metall Mater Trans A 2006;37:657.

[4] Kuramoto S, Furuta T, Hwang J, Nishino K, Saito T. Mat Sci Eng A 2006;442:454.

[5] Gutkin MY, Ishizaki T, Kuramoto S, Ovid'ko IA, Skiba NV. Int J Plast 2008;24:1333.

[6] Yano T, Murakami Y, Shindo D, Kuramoto S. Acta Mater 2009;57:628.

[7] Yano T, Murakami Y, Shindo D, Hayasaka Y, Kuramoto S. Scripta Mater 2010;63:536.

[8] Guo WY, Xing H, Sun J, Li XL, Wu JS, Chen R. Metall Mater Trans A 2008;39:672.

[9] Withey E, Jin M, Minor A, Kuramoto S, Chrzan DC, Morris Jr JW. Mat Sci Eng A 2008;493:26.

[10] Xing H, Sun J, Yao Q, Guo WY, Chen R. Appl Phys Lett 2008;92:151905.

[11] Yang Y, Wu SQ, Li GP, Li YL, Lu YF, Yang K, Ge P. Acta Mater 2010;58:2778.

[12] Xing H, Sun J. Appl Phys Lett 2008;93:031908.

[13] Yang Y, Li GP, Cheng GM, Wang H, Zhang M, Xu F, Yang K. Scripta Mater 2008;58:9. 
[14] Talling RJ, Dashwood RJ, Jackson M, Dye D. Acta Mater 2009;57:1188.

[15] Cui JP, Hao YL, Li SJ, Sui ML, Li DX, Yang R. Phys Rev Lett 2009;102:045503.

[16] Gordin DM, Delvat E, Chelariu R, Ungureanu G, Besse M, Laille D, Gloriant T. Adv Eng Mater 2008;10:714.

[17] Kim HY, Ikehara Y, Kim JI, Hosoda H, Miyazaki S. Acta Mater 2006;54:2419.

[18] Laheurte P, Prima F, Eberhardt A, Gloriant T, Wary M, Patoor E. J Mech Behav Biomed Mater 2010;3:565.

[19] Wang L, Lu W, Qin J, Zhang F, Zhang D. Mat Sci Eng A 2008;490:421.

[20] Abdel-Hady M, Hinoshita K, Morinaga M. Scripta Mater 2006;55:477.

[21] Wang L, Lu W, Qin J, Zhang F, Zhang D. J Alloys Compd 2009;469:512.

[22] Guo H, Enomoto M, Okuda K. Metal Mater Trans A 2000;31:599.

[23] Simkin BA, Ng BC, Crimp MA, Bieler TR. Intermetallics 2007;15:55.

[24] Niinomi M, Akahori T, Nakai M. Mat Sci Eng C 2008;28:406.

[25] Furubayashi E. J Phys Soc Jpn 1969;27:130.

[26] Caillard D. Acta Mater 2010;58:3504.

[27] Farenc S, Caillard D, Couret A. Acta Metal Mater 1993;41:2701.

[28] Castany P, Pettinari-Sturmel F, Crestou J, Douin J, Coujou A. Acta Mater 2007;55:6284.

[29] Castany P, Pettinari-Sturmel F, Douin J, Coujou A. Mater Sci Eng A 2008;483-484:719.

[30] Kim JI, Kim HY, Hosoda H, Miyazaki S. Mater Trans 2005;46:852.

[31] Obbard EG, Hao YL, Talling RJ, Li SJ, Zhang YW, Dye D, Yang R. Acta Mater 2011;59:112.

[32] Christian JW, Mahajan S. Prog Mater Sci 1995;39:1.

[33] Morris Jr JW, Hanlumyuang Y, Sherburne M, Withey E, Chrzan DC, Kuramoto S, Hayashi Y, Hara M. Acta Mater 2010;58:3271.

[34] Hao YL, Li SJ, Sun SY, Zheng CY, Hu QM, Yang R. Appl Phys Lett 2005;87:091906.

[35] Hao YL, Li SJ, Sun BB, Sui ML, Yang R. Phys Rev Lett 2007;98:216405. 


\section{Figure and table captions}

Figure 1. Microstructure of TNTZ (a) and TNTZ-O (b) alloys observed by optical microscopy

Figure 2. XRD from the TNTZ and TNTZ-O alloys at the recrystallized/quenched state

Figure 3. Conventional (a) and cyclic (b) strain-stress curves obtained from TNTZ and TNTZ-O alloys

Figure 4. SEM image showing the TNTZ alloy in a deformed zone after tensile test.

Figure 5. EBSD investigation of the TNTZ alloy after deformation until rupture: EBSD IPF map (a) and profile misorientation along $\mathrm{AB}(\mathrm{b})$

Figure 6. EBSD investigation of the TNTZ-O alloy after deformation until rupture: EBSD IPF map (a) and EBSD IQ map (b)

Figure 7. AFM topographic image (a) and profile of line deformations (b) on Gum Metal TNTZ-O deformed at $14 \%$

Figure 8. In-situ TEM micrograph showing formation of slip bands (SB) and slip traces of single dislocations (trace)

Figure 9. In situ sequence illustrating the typical motion of screw dislocation; on each frame, the previous position of the moving dislocation is highlighted with dashed lines; the white arrow pointed the formation of a dislocation loop by double cross-slip. See video as supplementary material.

Table 1. Mechanical characteristics of TNTZ and TNTZ-O alloys obtained by tensile tests. 

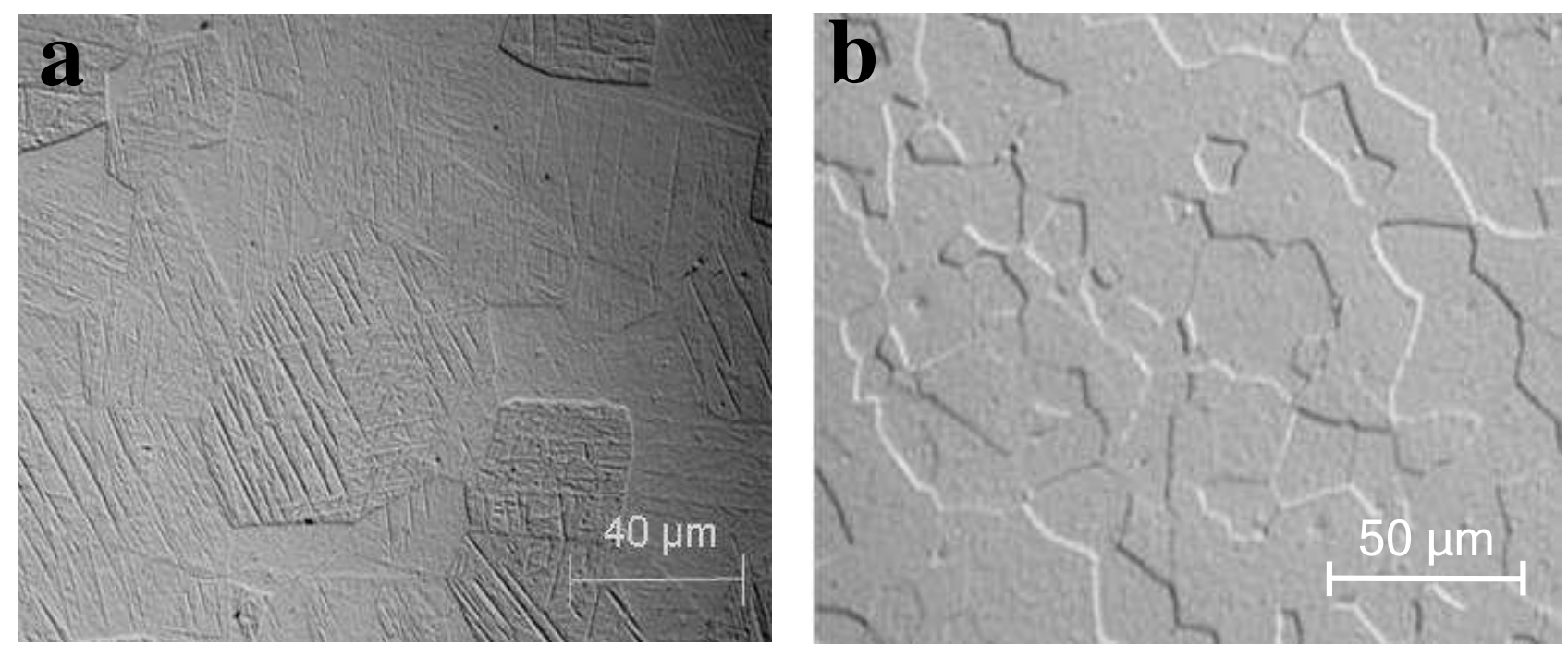

Figure 1 


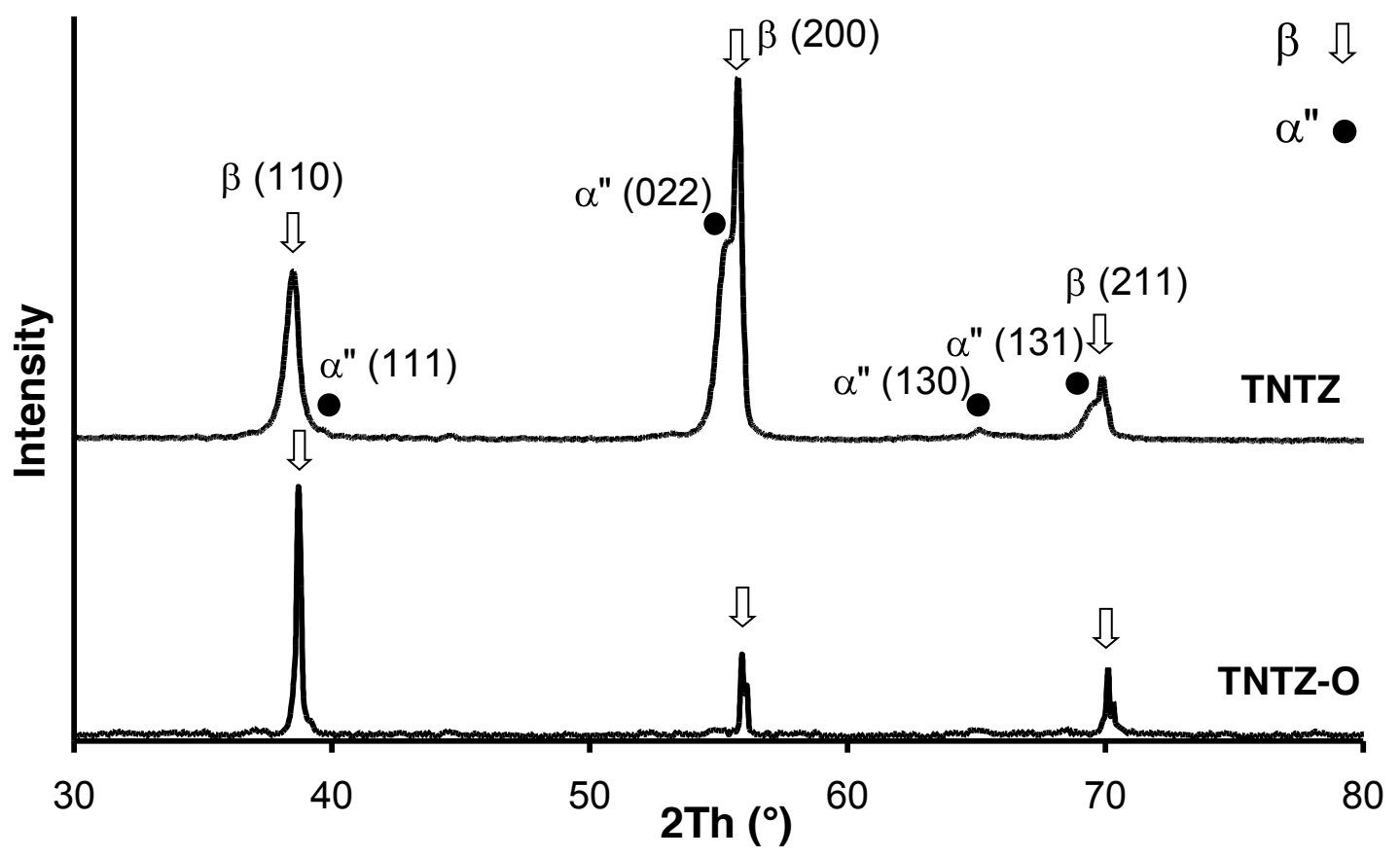

Figure 2 

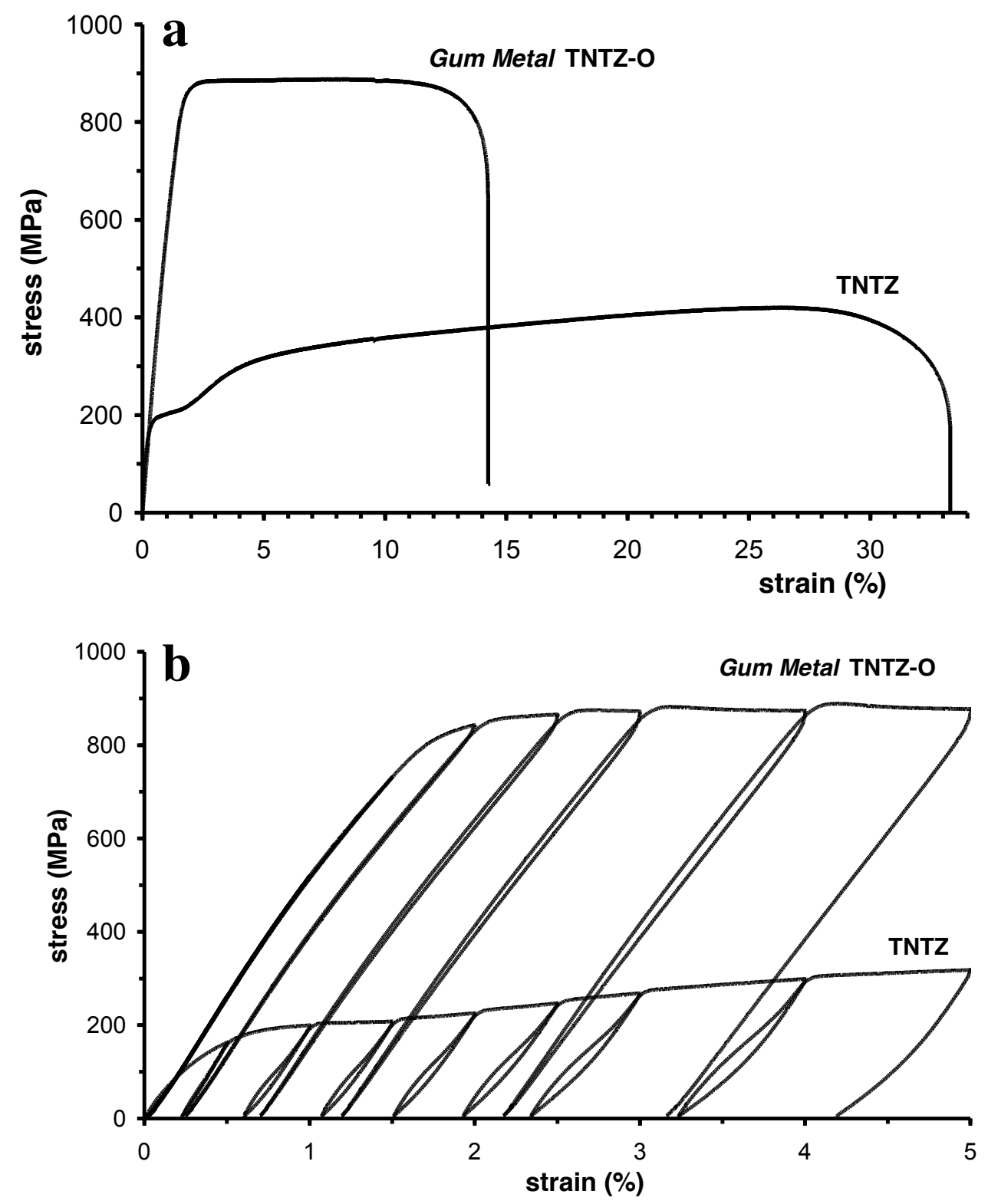

Figure 3 
Figure(s)

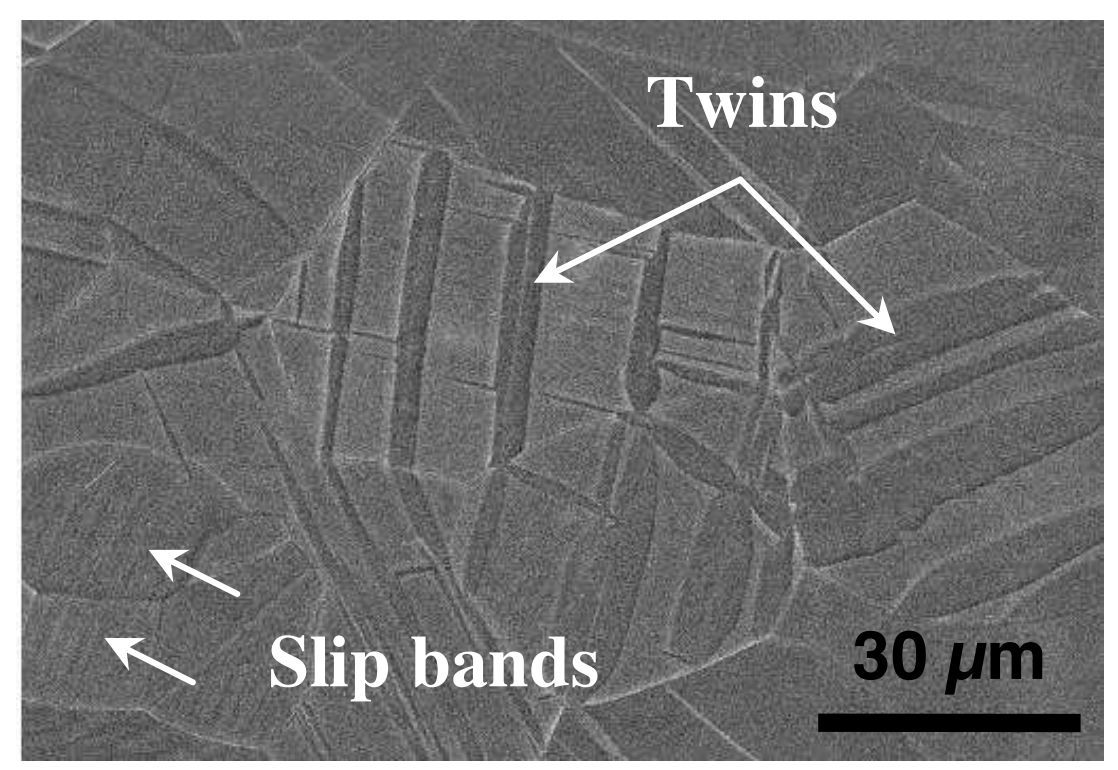

Figure 4

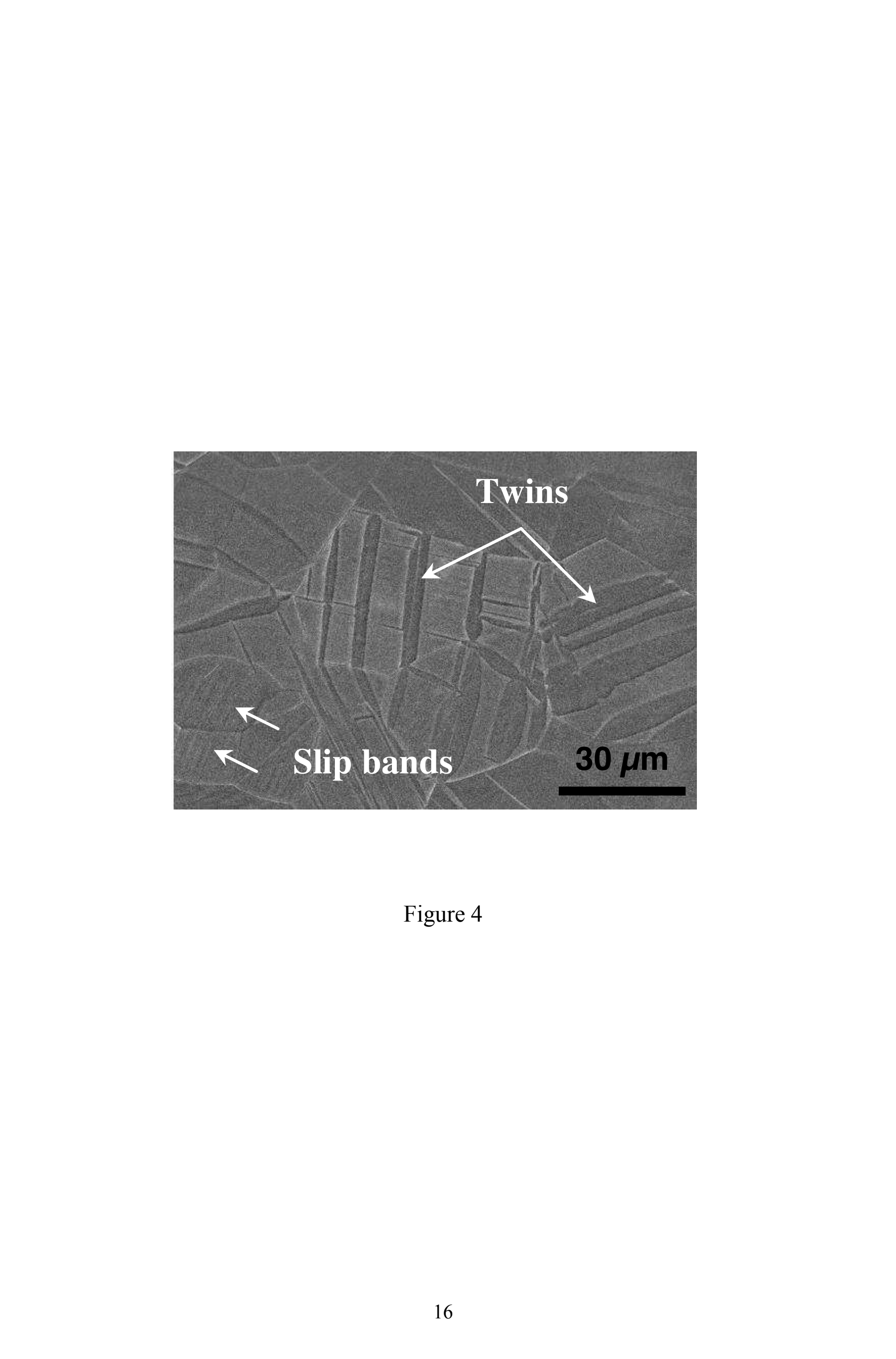

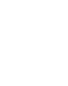

Twins

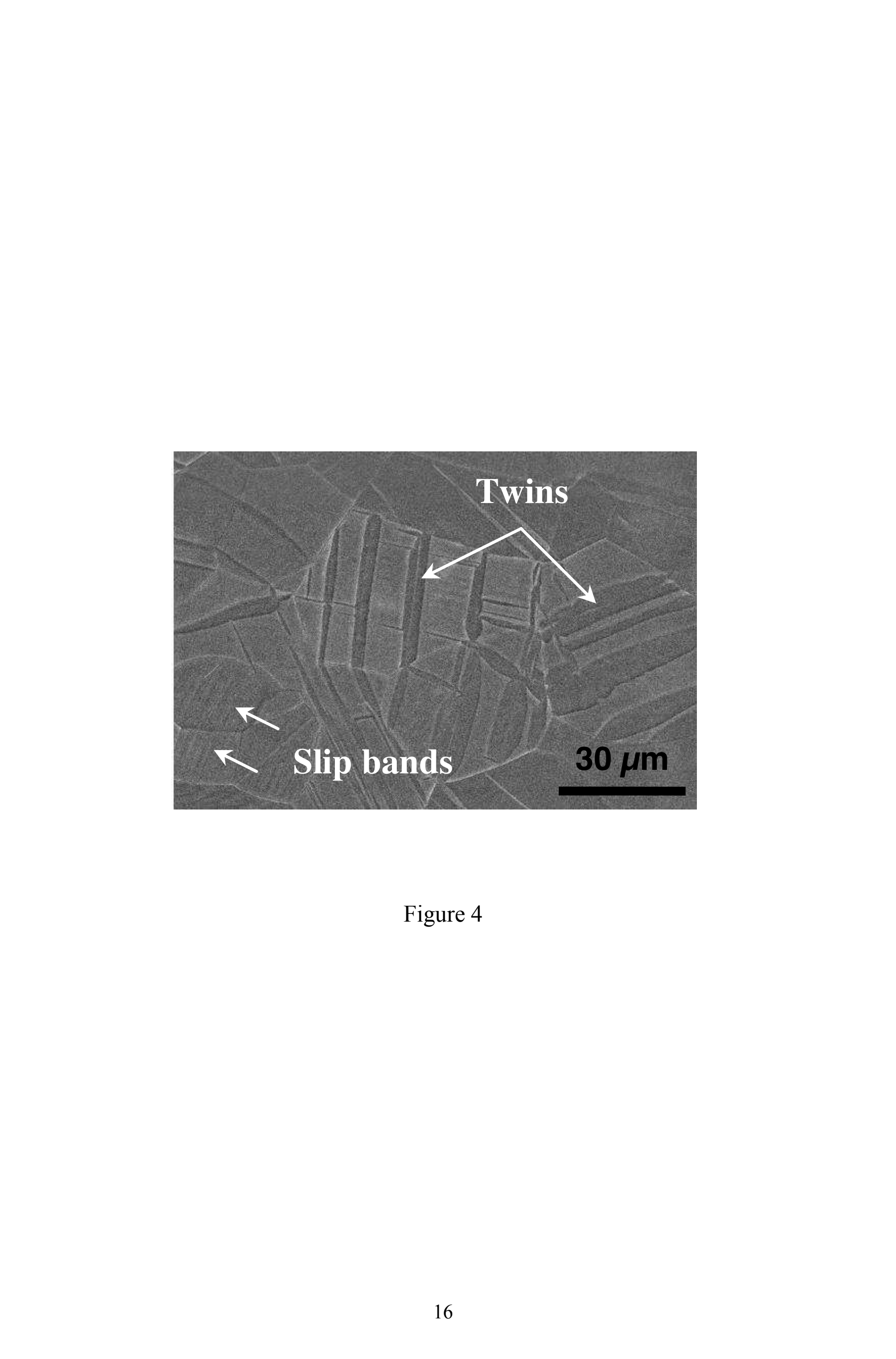

(
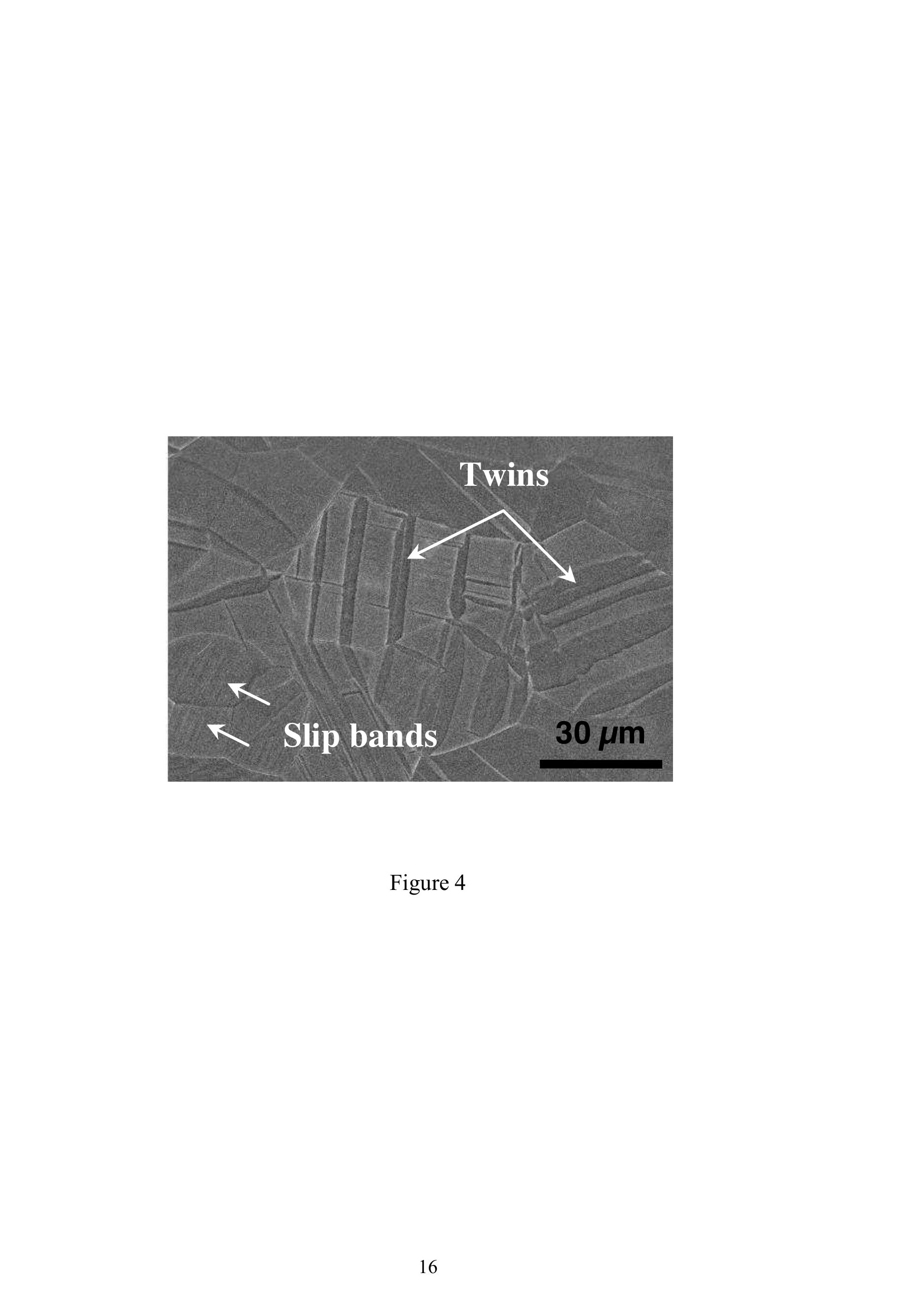

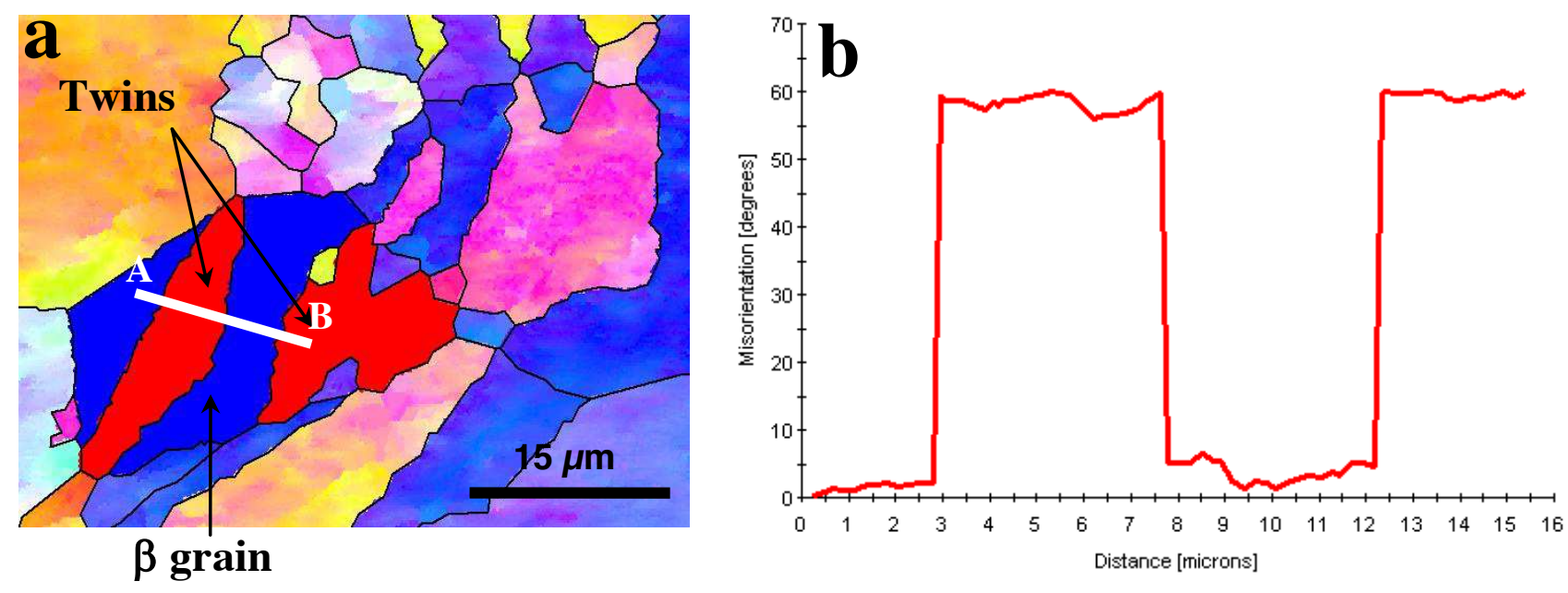

Figure 5 

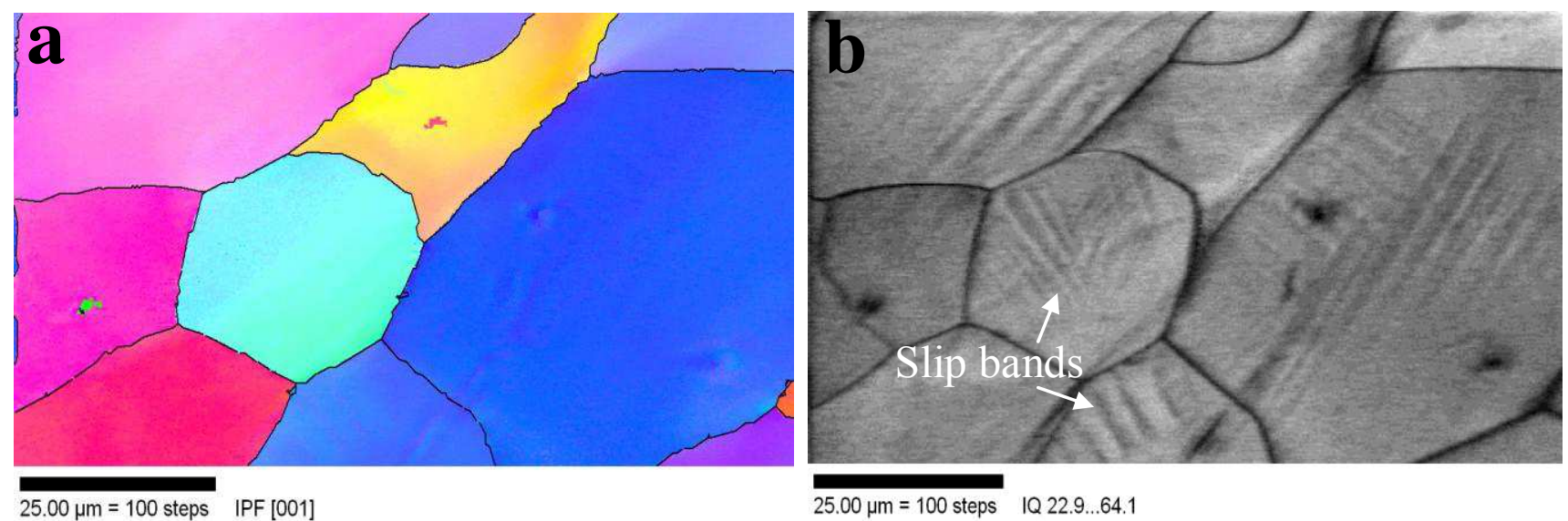

Figure 6 

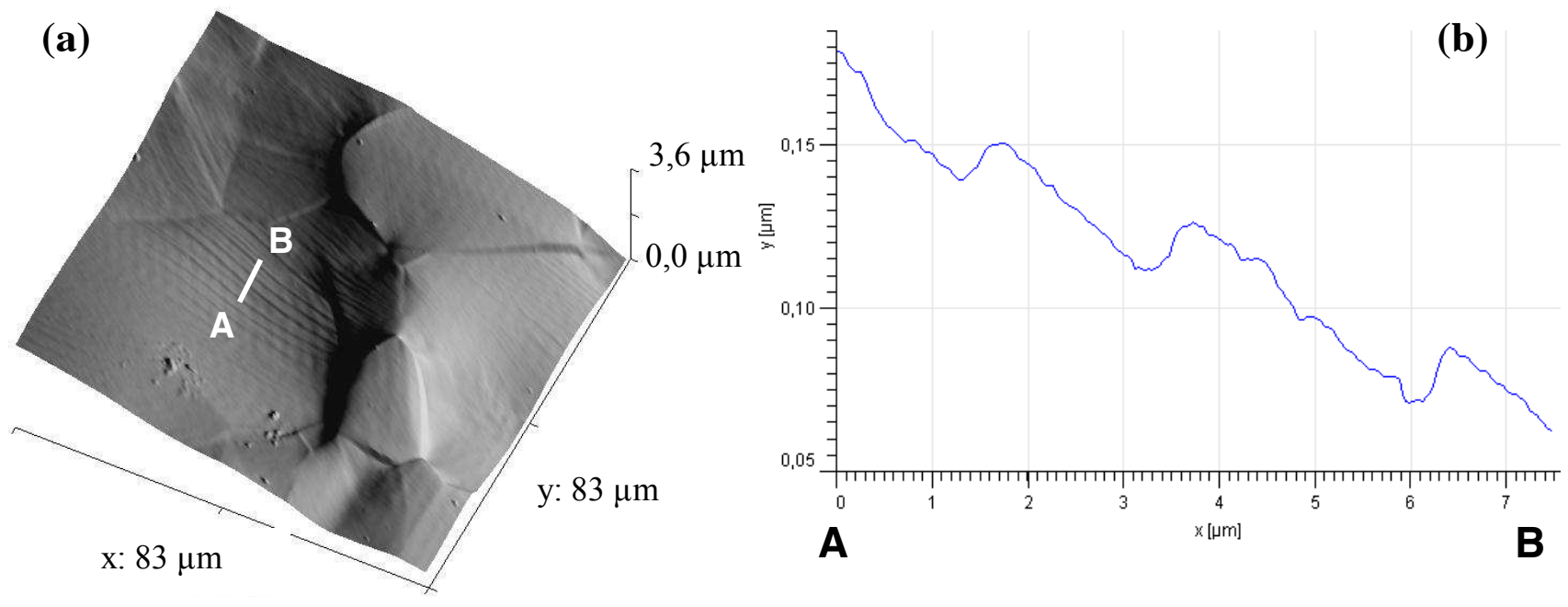

Figure 7 


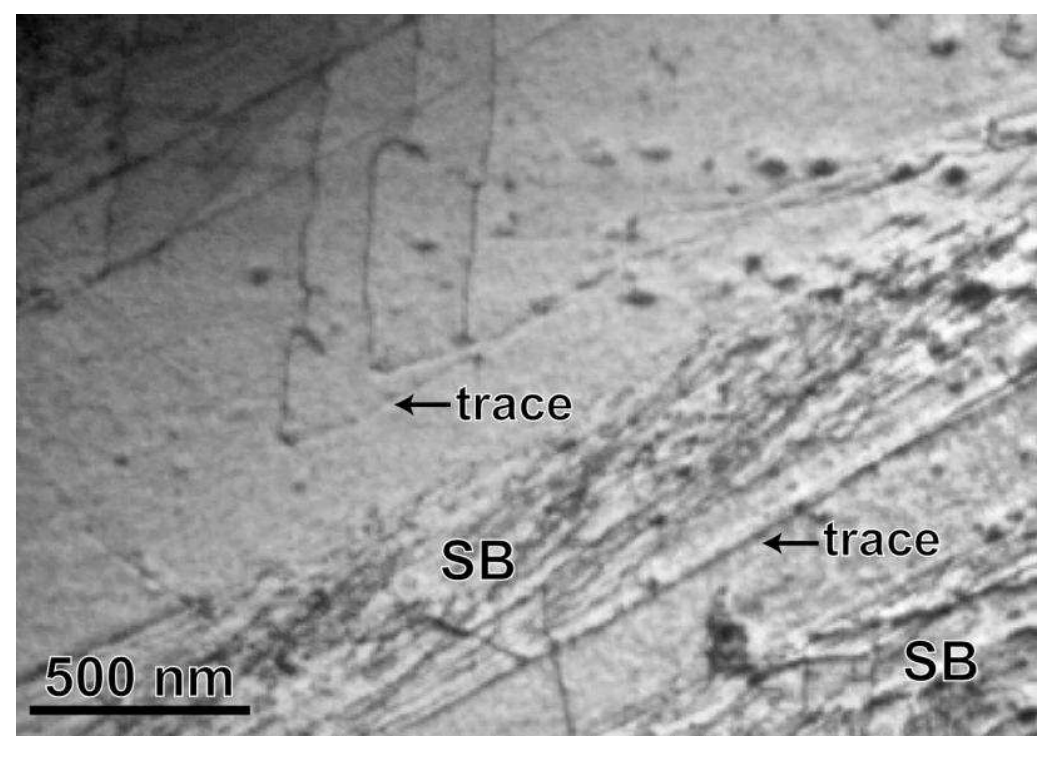

\author{
Figure 8 \\ Figure 8
}

\title{
Figure(s)
}

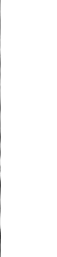

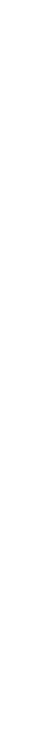

( 

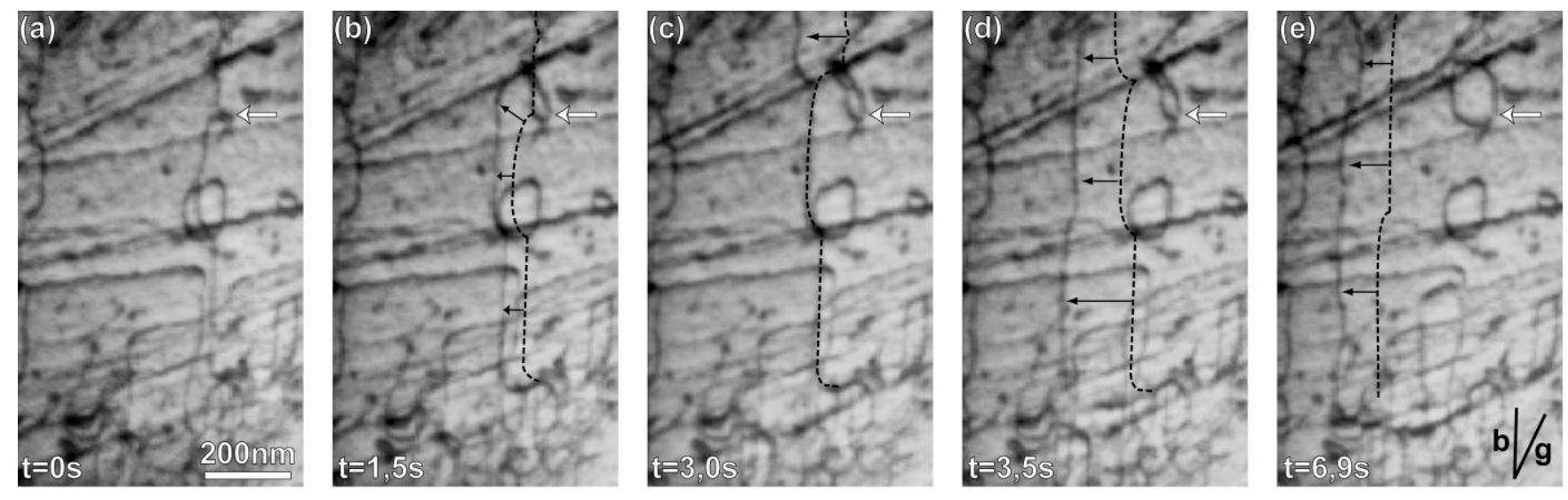

Figure 9 
Table 1

\begin{tabular}{|c|c|c|c|c|c|}
\hline ALLOY & YS, MPa & UTS, MPa & ER, \% & E, GPa & RES, \% \\
\hline TNTZ (this study) & $280\left(2^{\text {nd }}\right.$ YS $)$ & 400 & 33 & 55 & 0.25 \\
TNTZ-O (this study) & 830 & 880 & 14 & 60 & 1.5 \\
TNTZ-O (from [1]) & 850 & 900 & 19 & 65 & 1.2 \\
\hline
\end{tabular}

YS : Yield Strength UTS : Ultimate Tensile Strength ER : Elongation at Rupture

$E$ : Young's modulus $\quad$ RES : Recoverable Elastic Strain 
Supplementary Material
Click here to download Supplementary Material: Video.mov

Supplementary Material
Click here to download Supplementary Material: Video.mov

Supplementary Material
Click here to download Supplementary Material: Video.mov

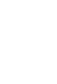

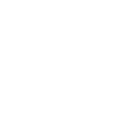

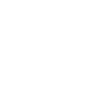

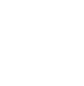

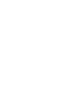
.

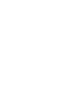
.

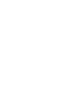
.

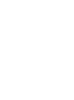
$+2$ -

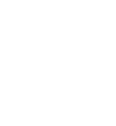

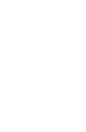

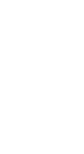

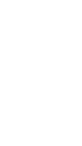

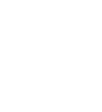

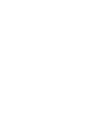

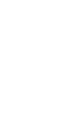

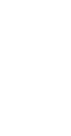

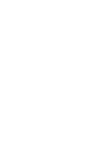

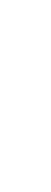
列

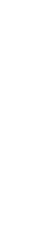

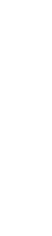

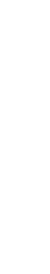
. .

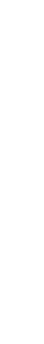
.

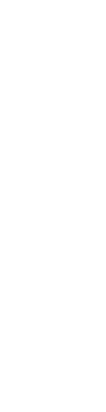
.

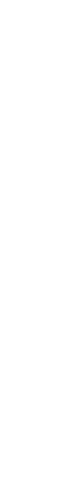
.

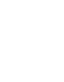

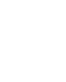

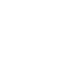

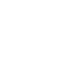
更 